\title{
Cyber Cemeteries as a Challenge to Traditional Reformed Thanatological Liturgical Praxis
}

Nicolaas Matthee

\section{Introduction}

This study aimed to critically analyze the use of cyber cemeteries and other forms of thanatechnology ("technological resources such as videos, computer-assisted instruction programs and interactive videodiscs that can be used to gain information about topics in thanatology", in a description by Carla Sofka) in a South African context, more specifically within the context of the Dutch Reformed Church (DRC), and their potential to enrich the current and future liturgical and ritual landscape. The concept of cyber cemeteries is interpreted in a way that includes a wide variety of death, grief and bereavement online; it is not only interpreted as specific websites dedicated to reproducing physical cemeteries in online spaces. The study further aimed to critically analyze existing liturgical praxis regarding rituals and rites concerning death and view these rituals and rites from the perspective that cyber cemeteries and other forms of thanatechnology contribute to our understanding of liturgy. This thesis intended to expand the way liturgy and ritual are understood in cyberspace and attempted to broaden the liturgical imagination regarding the liturgical possibilities in a digital society. On a more specific level, this study contributes to enhancing the cultural relevance of existing Reformed thanatological liturgical praxis, and the role of technology in participants' lives.

\section{Theory and methodology}

Chapter two explores theories to address these aims and the methodological implications for a study of this nature. In order for this to be possible, it develops a methodological framework based on classic network theory combined with insight from studies on the network society. It positions and understands this methodology in the larger context of the field of practical theology and therefore the field of liturgy is unpacked as a core component of the study. This discussion on liturgy draws on the work of Teresa Berger, Marcel Barnard, Cas Wepener, Johan Cilliers and Paul Post. Their work supports the exploration of liturgy and the network culture as core concepts in this thesis. In the last part of the discussion on methodology, the methods of ethnographic and empirical research are discussed with special attention to the context of cyberspace as the chosen research space. As part of the discussion on ethnography, the concept of a network ethnography is explored, combining concepts from the

* The thesis was accepted by the Faculty of Theology \& Religion, University of Pretoria, Hatfield, South Africa. Supervisor: prof. dr. Cas Wepener. Matthee is a Research Associate at the Faculty of Theology and Religion at the University of Pretoria. E-mail: nicframatthee@gmail.com. 
worlds of liturgy and technology to explain how ethnographic research is understood in this thesis. As a result, a model is developed to guide the ethnographic research as it was done in this thesis. The section on ethnography is concluded with a discussion on the ethical considerations as they pertain to doing ethnographic research in digital spaces.

The latter section of chapter two explores the general theoretical character of the thesis and emphasizes the concepts that were used to complete the research. Ritual and its place in modern society form a core part of the theoretical character of the thesis. This is explored in depth to understand how current developments influence the paradigms in which ritual is expressed. Flowing from the theory on ritual the discussion revolves around the theory regarding ritual studies and the importance thereof in the context of this thesis. Ritual studies is a key field in the context of the thesis. This is supplemented by considering the core concept of liminality, supported by important concepts such as disaster ritual and cyber ritual. As a final piece to the theoretical puzzle some important concepts from other disciplines are discussed, especially 'thanatechnology' and 'the post-mortal society'. The methodology, theoretical framework and core concepts gave the thesis the theoretical basis to explore ritual and liturgical expression in cyberspace.

\section{Findings, observations and descriptions}

Death and by extension cyber cemeteries serve as the lens to enable the observation of liturgical ritual in cyberspace. Chapter three presents and explores the findings from the field research and is introduced by reflecting on the nature of the participant observation that was used as the primary ethnographic method during the empirical research. This section discusses the process of planning the research and it also introduces the field sites. As the empirical research is of a qualitative nature, only five field sites are necessary to gather enough data. While the five field sites are all related to death they have subtle differences such as their age, the number of responses by the bereaved and whether or not the owner of the field site (Facebook profile) was deceased. Because of these and other differences between the field sites it was necessary to reflect on the limits of doing participant observation in cyberspace. Participant observation was a viable method of inquiry in the context of the research and the limitations were kept in mind when the results were analyzed and discussed. The field sites were further broken down to discuss the prominent codes that were evident in the data. The coding consisted of two parts. The first was an open coding process where the data of each site was explored, and codes were applied as certain topics and trends became evident in the data. Examples of this would be the different ways in which grief was expressed, and also the way in which the bereaved positioned themselves in relation to the deceased. This resulted in a large database of codes which was then narrowed down by applying a process of axial coding. The axial coding resulted in a higher quality dataset which was used to explore the different expressions of grief evident at the field sites. 
These expressions are discussed based on larger categories that include many of the expressions that were noted in the first phase.

After the account of the findings and observations made during the field research, parallels are drawn between the patterns that emerged from the data. Narrative is identified as a core theme, and equilibrium, liminality, disaster and disruption are explored as prominent concepts.

\section{The narrative nature of cyber ritual}

In chapter four, the theme of narrative as identified in the field research is examined to elaborate on the understanding of embodiment in cyberspace and the nature of space in cyberspace. To examine these two areas and their importance to ritual liturgical interaction in cyberspace, the chiastic structure of ritual and narrative is explored.

This is followed by an exploration of embodiment in cyberspace as the construction and encoding of a 'storied body': the physical body that undergoes different processes of encoding via cultural, social and other influences. This results in embodied code, in other words, a body that can be observed interwoven with code that cannot be physically observed. As the process transitions into cyberspace, the embodied code transforms into the codified body. In other words, the body loses the potential to be observed physically, and the code gains the potential to express the body. In the context of this thesis, a process of narrative deciphering took place where the codified body was deciphered. During the deciphering, the potential of the code was realized and expressed through narratives at the field site. The narrative(s) posted at the field sites constructed a body which could be observed through the story told about it; therefore, the deciphering delivered the storied body. If the process was linear, this would have been the end and the process would restart from the body as described at the start. As the process is a hermeneutical spiral, the storied body is also encoded through the narrative (its own or other narratives expressed at the site). As the process moves back to the corporeal dimension, the narrative encoding of the body results in a newly formed codified body. From a ritual liturgical perspective, this codified body is not the same as the one that entered moments before. The code has been changed based on the experiences in cyberspace. When the person logs out of Facebook or the platform of choice, the body regains its potential for expression, expression that is rooted in the codes interwoven in the body. The new code is deciphered and the body is enhanced in the process.

The development of this concept is followed by the exploration of the nature of space in cyberspace. The concept of space is approached from a perspective of boundedness, in other words, space as it becomes evident by the factors that define it. The nature of space in cyberspace is explored based on certain themes that include spatial proximity, public space, authenticity and virtual worlds. The conclusion of this chapter explores the potential for a narrative construction of space in cyberspace, followed by a short critique of the concept of narrative as it is used in the context of this thesis. 


\section{Conclusions}

During the course of this research, the reality of cyber cemeteries has challenged various constructs, theories and beliefs that relate to the sphere of ritual and liturgical studies. Specific emphasis was placed on the understanding of embodiment in cyberspace and the nature of space in cyberspace. These two crucial areas were chosen based upon the data gathered during field research. In addition, the research data pointed toward a narrative understanding of 'embodiment' and 'space' in cyberspace to make them applicable to the praxis of traditional Reformed thanatological liturgical praxis.

The challenge posed to traditional funeral liturgies as they are to be found in the literature of the DRC can be traced back to one of the first points made in this thesis, that practical theology should be open-ended, flexible and porous. This attitude toward doing practical theology is important, especially when the context of liturgical expression is experiencing a dramatic shift. This shift toward cyberspace is simply following the worldwide trend in the 21st century, but it would seem that the boundaries of the thanatological liturgical praxis of the DRC do not (know how to) allow space for this natural movement observed in the cultural shifts of humanity.

The understanding (or lack of understanding) of constructs such as space and embodiment is proving to be detrimental to the evolution of liturgy in the DRC. This does not imply that the current attitude and literature of the DRC actively prohibits such evolution or migration, but rather that the way in which practical theology is done needs a re-evaluation in the light of the way in which liturgy is understood. Cyberspace and specifically cyber cemeteries themselves are good examples of how fluid boundaries are in the network culture. Participants have the ability to create, construct and reproduce space almost instantly. This is evident from the iterations of cyber cemeteries as observed on Facebook and the memorial website to Chester Bennington. Liturgical spaces of mourning were constructed in cyberspace and in a relatively short amount of time they evolved from physical reproductions of cemeteries online, to dedicated places of mourning online (not necessarily a reproduction of a cemetery), to spontaneously constructed spaces on Facebook, Instagram etc., to virtual memorials in digital games and most recently liturgical expressions that disappear after 24 hours in the form of a 'story' on platforms such as Facebook and Instagram.

Therefore, the thinking around liturgy and ritual liturgical expression needs to be rooted in paradigms that are open-ended, flexible and porous, otherwise, the context of cyberspace will be particularly difficult to traverse. As mentioned earlier, there were two concepts that emerged from the research data: embodiment and space. These concepts are indicators of areas in which traditional Reformed liturgy is challenged by the context of cyberspace.

\subsection{The challenge of embodiment}

The first pattern that emerged from the data was that of embodiment. The question was whether cyberspace and ritual liturgical expression in cyberspace prompted any changes to human beings them- 
selves, or not. This was not tested in terms of interviews and other ethnographic methods, but the theory developed, based on the observations made at the field sites, would suggest that experiences in cyberspace do indeed have authentic consequences for the people involved.

Based on the process developed and discussed as the storied body in chapter four, the importance of experiences in cyberspace as encoding our physical bodies (much like they are culturally encoded) cannot be ignored. Granted the DRC does not have any official cyber rituals or liturgies (excluding services being streamed online), this does not mean that members of the congregations of the DRC do not participate in ritual liturgical activities elsewhere. It is likely that members of the congregations are participants in many cyber rituals without necessarily being aware that this is the case. This raised the question: 'how does the traditional Reformed thanatological liturgical repertoire account for participants who have already experienced much that the traditional liturgies offer?' The process is akin to a hermeneutic spiral and many of the participants have likely become part of online liminal communities and started to weave their own narratives of grief. This thesis does not argue that the traditional liturgy has lost its place or become irrelevant; the reality is simply that the thanatological context has changed to such a degree that traditional approaches do not respond to the struggles and challenges of 21st-century citizens.

To conclude, the concept of storied bodies as part of the context of cyber ritual and liturgical expression with regards to death challenges the traditional liturgical concepts of the DRC with regard to funerals, death and mourning in such a way that warrants a re-evaluation of the current position of traditional thanatological liturgical praxis as performed in the DRC.

\subsection{The challenge of space in cyberspace}

The second pattern that emerged from the data was that of space as it pertains to cyberspace. It was found that space was narratively constructed in cyberspace; therefore, participants had the ability to construct space based on the narratives they shared. This ability to construct space was observed throughout the research done at the field sites and participants created a wide variety of mourning spaces through their narratives.

Just as corporeal space is bound by certain limits, space in cyberspace is also bound and it is in the boundedness of the space that its nature comes to the fore. Space in cyberspace has the potential to be both a creative space and a transcendental space where authentic experiences are to be had. Therefore, it is possible that space in cyberspace can be sacred and facilitate ritual liturgical expression. Furthermore, it was found that spaces in cyberspace, while having many similarities with corporeal space, are also virtual worlds. The challenge then to the traditional thanatological liturgical praxis of the DRC is in knowing that members of the various congregations are four-dimensional human beings. This means that they are participants in both corporeal and virtual spaces, and therefore they are formed by and in both of these spaces. The literature of the DRC and the liturgical guidelines, indicates 
that not much is made of other spaces than the traditional liturgical spaces. In a post-mortal society these 'other' spaces feature prominently in the lived reality of the members of the congregations.

Most modern businesses employ the services of a social media manager or a digital marketing agent with the specific aim of engaging the space of cyberspace. What would the equivalent be in the DRC? Is it necessary to actively engage with the space of cyberspace? These are questions that the reality and authenticity of the space pose to the DRC. The praxis of traditional Reformed liturgy regarding death is also fundamentally challenged as the corporeal church space is not the only space where rituals of mourning are performed. As is evident from the research done for this thesis, cyberspace is a popular space for ritual liturgical expression regarding death and people participate in this space for years after the death of the person being remembered/mourned.

\subsection{Final thoughts}

Cyberspace and ritual liturgical expression in cyberspace are indeed areas of immense complexity. Within these complexities lies the opportunity for a new and evolved ritual repertoire, forged in the context of the late 2oth century and continued in the 21st-century. Cyberspace is an important area of inquiry for practical theology and will only increase in importance as the century progresses. With the network society at its center, people have never been as connected as now. Communities are formed across vast distances with people from a wide variety of cultures and backgrounds. Through the examination of cyber cemeteries, it is evident that cyberspace is also a space where liminal communities are formed and thrive. The very nature of the space is amenable to the concept of liminality. It is also evident that notions around the understanding of specifically embodiment and space are fundamentally challenged by the reality of cyberspace. The way in which these concepts are challenged raises critical questions about the thanatological liturgical praxis of the DRC. It is the position of this thesis that Reformed liturgy as illuminated by the literature of the DRC, cannot remain unchanged in the face of the challenges issued by the context of cyberspace. Liturgy will need to embody the value of flexibility and be porous enough to ensure that there is enough space for the multitudes of ritual liturgical expressions made possible by the reality of cyberspace.

The aim of this study was to inquire into the ways in which cyber cemeteries and other thanatechnology influence ritual liturgical expression. A research result was that Facebook (primarily) and other memorial sites offered much in terms of understanding ritual liturgical expression in cyberspace. Ritual liturgical expression in cyberspace appeared to be strongly influenced by the narratives of the individuals in encoding and decoding their bodies as they moved between the dimensions of cyberspace and corporeal space. Another outcome was that narratives were responsible for the construction of ritual liturgical space, and that the narratives that constituted the space in cyberspace could create a context where the sacred could be experienced. 
Cyberspace will remain a valuable area of inquiry into the nature of ritual liturgical expression for the foreseeable future. Not many things in life are certain, but for the time being death is a certainty. Therefore, liminal communities of mourners will use cyberspace and its iterations to express their narratives of grief. 